\title{
Hydrogen rich gas from oil palm biomass as a potential source of renewable energy in Malaysia
}

\begin{abstract}
Oil palm is one of the major economic crops in many countries. Malaysia alone produces about $47 \%$ of the world's palm oil supply and can be considered as the world's largest producer and exporter of palm oil. Malaysia also generates huge quantity of oil palm biomass including oil palm trunks, oil palm fronds, empty fruit bunches (EFB), shells and fibers as waste from palm oil fruit harvest and oil extraction processing. At present there is a continuously increasing interest in the utilization of oil palm biomass as a source of clean energy. One of the major interests is hydrogen from oil palm biomass. Hydrogen from biomass is a clean and efficient energy source and is expected to take a significant role in future energy demand due to the raw material availability.

This paper presents a review which focuses on different types of thermo-chemical processes for conversion of oil palm biomass to hydrogen rich gas. This paper offers a concise and upto-date scenario of the present status of oil palm industry in contributing towards sustainable and renewable energy.
\end{abstract}

Keyword: Hydrogen; Oil palm; Gasification; Thermo-chemical; Energy 